\title{
Qualitative Study on Postoperative Self - identity in Patients with Temporary Ileostomy
}

\author{
Lili Fan ${ }^{1}$, Fang $\mathrm{Hu}^{2}$ \\ ${ }^{1}$ Tianjin Third Central Hospital, 300170 \\ ${ }^{2}$ Medical University Of Tianjin, 300070
}

Abstract: The purpose is to understand the postoperative self-identity of patients with temporary ileostomy and to provide a clinical basis for the development of psychological interventions by stoma therapists. Method:Selecting 10 patients intentionally who underwent temporary ileostomy for 1 month and testing via one-on-one in-depth interviews and analyze data with Claizzi analysis program. Results:One month after surgery, patients' self-identity can be summarized into three topics:(1) inferiority complex and disgust mood; (2) adaptation and coping; (3) social value experience change. conclusion:Temporary ileostomy Patients' psychological experience within 1 month after the surgery is complicated. In this study, the purpose is to dig out the true experience of such patients in the heart by analyzing 10 cases of patients with temporary ileum after 1 month in-depth interviews, so that we can aware of these patients in self-identity on the existence of the three main problems. Remind the stoma therapists pay attention to the After surgery early social psychological adaptation; strengthen information delivery and emotional support; helping rebuild self-identity, for the realization of self-care return to normal social life is of great significance and provide a reference for clinical pathological nursing patients after ostomy..

Keywords: Temporary colostomy; postoperative; self-concept; qualitative study

Ileostomy because of its complications is more difficult to be cared in clinical surgery and is more likely to be seem as a temporary intestinal transit, in order to facilitate anastomotic healing ${ }^{[1]}$. Self-identity is the individual's self-reflective understanding of personal experience. Since 1963, Erickson put forward the concept of "self-identity", it has been widely used in psychology and sociology. Regarding the relationship between "self-identity" and the body, he believes that the embedding of the body in daily life is the basic way to maintain a coherent sense of self-identity ${ }^{[2-3]}$. Patients with enterostoma due to physical changes, result in changes in patient self-identity, seriously affecting their quality of life.

This article uses a qualitative approach that explores the changes in self-identity of patients after temporary ileostomy.

Hoping to provide a reference basis for the targeted psychological counseling for stoma therapists and such patients

Copyright (C) 2018 Lili Fan et al.

doi: 10.18686/jn.v7i1.145

This is an open-access article distributed under the terms of the Creative Commons Attribution Unported License

(http://creativecommons.org/licenses/by-nc/4.0/), which permits unrestricted use, distribution, and reproduction in any medium, provided the original work is properly cited. 


\section{Objects and methods}

\subsection{Research object}

Adopting intentional sampling method. Ten patients (one month after temporary ileostomy) were enrolled in the general surgery department of a tertiary teaching hospital from January 2015 to January 2016.

The standard for sample termination of qualitative research is that respondents' data is repeated, and no new topics are presented during data analysis (Data saturation) ${ }^{[4]}$. In this study, the number of samples reaching saturation was 10. The general information of interviewees is shown in Table 1

\begin{tabular}{|c|c|c|c|c|c|}
\hline Number & Sex & Age & $\begin{array}{c}\text { Education } \\
\text { Level }\end{array}$ & Occupation & $\begin{array}{c}\text { Marital } \\
\text { Status }\end{array}$ \\
\hline 1 & female & 29 & $\mathrm{Ph} . \mathrm{D}$ & technician & unmarried \\
\hline 2 & female & 74 & illiterate & none & Widowed \\
\hline 3 & female & 69 & $\begin{array}{l}\text { junior high } \\
\text { school }\end{array}$ & retired & married \\
\hline 4 & male & 54 & $\begin{array}{l}\text { junior high } \\
\text { school }\end{array}$ & worker & married \\
\hline 5 & female & 75 & $\begin{array}{l}\text { junior high } \\
\text { school }\end{array}$ & retired & married \\
\hline 6 & male & 71 & $\begin{array}{r}\text { primary } \\
\text { school }\end{array}$ & none & married \\
\hline 7 & female & 43 & high school & worker & unmarried \\
\hline 8 & male & 47 & college & cadre & married \\
\hline 9 & male & 66 & $\begin{array}{l}\text { junior high } \\
\text { school }\end{array}$ & retired & married \\
\hline 10 & female & 70 & $\begin{array}{l}\text { junior high } \\
\text { school }\end{array}$ & retired & married \\
\hline
\end{tabular}

Table 1 The general information of interviewees

\section{2 research methods}

\subsubsection{Case of ethical issues}

Before the interview, we introduced the purpose and significance of the study to the patients and promised not to leak the patient's personal information. All information obtained will be used for research without any harm to the patient.

With the patient's consent, signed informed consent. The whole process of interviewing uses a unified guideline, which follows the principle of non-injury of nursing ethics. 


\subsubsection{Interview process}

\subsubsection{Interview outline design}

After information access, expert guidance, and constantly improve several steps the outline of the interview was completed. The outline mainly includes three aspects.

Patient's personal data, general questions, in-depth interview topics.

General questions include "What is your primary reason for being hospitalized," "What have you done since you were hospitalized," etc., to establish initial understanding and trust with your patients through the exchange of general questions. In-depth interview topics include "When did you know you had a stoma? "'What do you think the first feeling after seeing a stoma?" "How do you feel after surgery?" "What do you think about yourself after surgery?" "What do you think the people around you feel about your changing? "' What do you think about your future work and life?"

\subsubsection{Data collection}

With reference to a pre-designed interview outline, the researchers collected information through one-on-one face-to-face and semi-structured interviews, without any guidance or suggestion.

Select patients who are going to discharge, the physical condition of these people can adapt to the conversation, and they can cooperate well. Talk in quiet environment, carried out in the natural context, each patient was being interviewed for $30 \sim 40 \mathrm{~min}$. During the interview, the data were saved by way of recording.

\subsubsection{Data analysis and organising}

Use Claizzi phenomenological analysis program ${ }^{[5]}$ for data processing and analysis. (1) Data collection and analysis will be collected after the interview, and respondents will be confirmed within 24 hours to ensure the authenticity of the data. (2) carefully read the interview records, extract significant statements. (3) coding recurring meaningful point of view. (4) The encoded views of the collection, write a detailed, without omission description. (5) identify similar ideas, sublimate theme concepts.

\section{Results}

Through the analysis of the data, induction, explore the true inner thoughts of patients with temporary ileostomy, the common part of the researchers in the language.

\subsection{Inferiority and disgust mood}

Personality factor is an important factor affecting postoperative psychological adjustment. Physical changes can shake the positive aspects of the patient's self-concept and cause the patient to show some withdrawal behavior. Most patients in this interview have depression, low self-esteem, dependence and other negative emotional fatigue.Patient 1 said: "When I first saw my stoma, it made me feel dizzy and almost fainted. I secretly cried several times." "I am 29 years old and my life was over ..." Patient 8 said: "In addition to answering other people's questions in these days, I only want to be alone and do not want others to ask me." "If possible, I want to hide myself and hide it Everyone did not know where. "Patient 7 said:" I would rather stay in the bathroom, I do not want to go out, if others dislike me, I do not want to live ......".

\subsection{Adapt and response}

Although many behaviors of patients are dominated by bad mood, some patients can still find positive coping styles. Patient 4 alleviates his sadness by comparing to the down society: " I am able to do the surgery and I can live by stoma, I think I am much luckier than those who can not do surgery " Downward society comparison refers to compare their own individual and the people who in a poorer condition, so that people can reduce individual self-evaluation frame of reference in order to maintain a positive self-evaluation, which is one of the mechanisms to deal with stressful 
events and maintain mental health, adapt to function well ${ }^{[6]}$. The interview found that patient 3 adopted a meaningful response, mainly referring to the fact that some patients chose to change their original beliefs, values and goals due to the fact that they could not to change this facts, which means people are eager to adapt to the status quo well ${ }^{[7-8]}$. He said: "I have to accept it, because I must survive in this condition. Anyway, it will be back to normal in a few months." "It's probably okay to get used to it."

\subsection{Changes in social value experience}

Self-identity changes when the patient's body experiences something that has not changed. Interviews found that Some patients have doubts about their social value. Referring to the plan for future work, Patient 8 said "I do not want to do anything now because I do not know what I can do when I recover." Patient 7 said "

I do not know whether the company will continue to hire me after knowing my physical condition. "Patient 4 feels that he is burdensome for the family:"

However, after experiencing the test of life and death, some patients also have enhanced their understanding of their own social values. Patient 6 said: "

After experiencing this serious illness, I feel my life is more precious. I will not give up on myself, because my life is so difficult to get through, I insist to now, how there are reasons not to go on drifting it? "Patient 5 said:" I believe my existence is a kind of wealth for my family and I believe that have a lot of value for society ."

\section{Discussion}

The patient who got though the Temporary ileostomy surgery underwent the surgical trauma and excretion of this pathway. They have some changes in self-identity and depression, which are prone to intense psychological stress.

\subsection{Emphasis on early social psychology}

Since January was only an initial experience, its personal growth was not significant, but the study found that patients alleviate the negative emotions through downward social comparisons and seek a sense of belonging to strengthen the "can be recognized by society" consciousness. At this point, the patient is in an important turning point in the social psychological adaptation. At this stage, on the one hand, nurses can take the suggestion and other methods to stimulate patients to produce effective response or enhance their original effective coping style; on the other hand, by encouraging the exchange of patients, to recommend patients with Stomatological Association, patients will help patients get useful coping experience and information, enhance their social identity, and gradually establish a wider range of interpersonal relationships, to improve the patient's psychological stress and promote their psychological growth provides a good start.

\subsection{To enhance information delivery and emotional support}

Interviews found that patients generally have increased their need for emotional support. They are eager to get their family and society acceptance. They have a normal social exchange platform and can live in dignity. And the need for communication with health care professionals is especially obvious. However, these needs are hardly satisfied by simple "comfort".

Therefore, the ostomy therapists provide them with the professional knowledge and the latest advances in stoma,.Psychological counseling according to stage can provide patients with better and more comprehensive help.

\subsection{Re-establish self-identity}

Intestinal stoma patients have negative emotions and emotional fluctuations ${ }^{[7]}$. This study found that the change of self-identity is the source of many emotional experiences, and also changes the positioning of patients for their own existence value. After ostomy, due to surgical stress and body shape changes, patients need to re-understand their own body, the responses from others also need to be re-evaluated,only by gradually establishing a self-identity conforming to their physique can a positive emotional reaction be produced and the social value experience can be 
restored. Self-identity enhancement needs the patient's own adjustment, also need medical staff and their families intervention. Active communication and exchange, purposeful intervention and advice are catalysts for accelerating this process.

\section{Summary:}

In this study, the purpose is to dig out the true experience of such patients in the heart by analyzing 10 cases of patients with temporary ileum after 1 month in-depth interviews, so that we can aware of these patients in self-identity on the existence of the three main problems. Remind the stoma therapists pay attention to the After surgery early social psychological adaptation; strengthen information delivery and emotional support; helping rebuild self-identity, for the realization of self-care return to normal social life is of great significance and provide a reference for clinical pathological nursing patients after ostomy.

\section{References}

1 Hu Ailing, Zheng Meichun, Li Weijuan. Modern wounds and intestinal stoma clinical nursing practice [M]. Beijing: Peking Union Medical College Press, 2010: 276-279.

2 Erickson, A.H. Identity: Adolescents and Crisis [M]. Sun Mingzhi, translated. Hangzhou: Zhejiang Education Press, 1998.

3 Giddens, A. Modernity and Self-identification: Self and Society in Late Modern Times [M]. Zhao Xudong, Fang Wen, translated. Beijing: Living $\bullet$ Reading $\bullet$ Shinwoo Joint Publishing, 1998.

4 Greenslade J H, Jimmieson N L. Distinguishing between task and contextual performance for nurses: Development of a job performance scale [J]. J Adv Nurs, 2007, 58 (6): 602-611.

5 Zhou Xian, Hu Zhong-feng. Theoretical discussion and reflection on qualitative research methods [J] .Guangdong Social Sciences, 2015,04: 51-57.

6 Jiang Gan gold. Medical Psychology [M]. Beijing: People's Medical Publishing House, 2010: 25,107-108.

7 Zhai Jianxia, Jiang Hong, Wu Jing, et al. Qualitative study on post-traumatic growth in patients with severe burn [J]. Zhonghua Nursing Journal, 2011,46 (7): 694-696.

8 Chen Hailian, Yang Xiaofei, Lin Lihua, Li Bijun, Wang Bin, Wang Yuezhen, Ye Qin Yong. Self-efficacy theory in improving bladder cancer urinary stoma patients coping style and quality of life $[\mathrm{J}]$. Chinese Nursing Education, 2016, 02: 89-92.. 